\title{
Association for Library Collections and Technical Services Annual Report 2016-17
}

Vicki Sipe, ALCTS President 2016-17

$\mathbf{W}$ or sixty years, the Association for Library Collections and Technical Services I (ALCTS) has provided opportunities in education, discussion, publishing, and collaboration to the library community. A division of the American Library Association (ALA), ALCTS is the premier organization for professionals in acquisitions, collection management, cataloging and metadata, continuing resources, and preservation. Our engaged members lead the way in developing standards and best practices for creating, identifying, selecting, acquiring, organizing, managing, and preserving recorded knowledge in all formats. This annual report summarizes our activities for the 2016-17 year.

\section{0th Anniversary of ALCTS}

Celebrating a diamond anniversary is a big job, and two groups were charged with creating a variety of events to mark the special occasion. The 60th Anniversary Steering Group, under the leadership of Dina Giambi, provided several events throughout the year. A forum at Midwinter brought together a panel of ALCTS leaders sharing personal histories and organizational achievements. It celebrated lifelong friendships rooted in ALCTS, outreach to welcome new members, and giving back to the profession through our many ALCTS programs. An e-Forum held in mid-June asked members to consider the impact of ALCTS on careers and personal lives. The Steering Group also coordinated a $\$ 60$ for 60 fundraising campaign with every donor recognized as a Diamond Donor. The campaign exceeded all expectations, raising over $\$ 15,000$ by April 2017 . A friendly competition among the ALCTS sections over which would have the highest percentage of participation concluded with recognition of the winning section at the ALCTS Awards Ceremony during ALA Annual in Chicago. It is noteworthy that the ALCTS Board led the way with 100 percent participation in this personal giving campaign.

The Exchange Working Group, led by Karla Strieb, concentrated on a singular event held over several days. The entirely online event took place over four days in four-hour sessions of live streaming presentations and activities. A website for the event includes readings, drop-in chat spaces, virtual posters, and recordings of the live stream activities. It will remain available to registrants of the event for a year. Over 300 user accounts were created to access materials. Feedback 
assist ALCTS with future program planning, and others expressing interest in presenting at future ALCTS events. Many complimented the breadth of the topics touched upon during the four days. This time and labor intensive experiment in programming has created recognition and credibility for ALCTS among new networks of colleagues and around a broad range of topics.

Though not specifically focused on the anniversary, it is appropriate that the ALCTS Mentoring Program began in this diamond anniversary year. We have a long history of informal mentoring within ALCTS, and organized programs through the Cataloging and Metadata Management Section (CaMMS) Recruitment and Mentoring Committee. This new program intends to augment our existing networks. The ALCTS Mentoring Subcommittee, under Regina Gong's leadership, has worked tirelessly for over a year to bring the program to fruition. In what we hope will become an annual event, the first cohort of ALCTS mentors and mentees began their partnerships on June 1.

\section{Financial Sustainability}

Over the past several years, ALCTS has very strategically reduced expenses with the goal of a balanced budget. These efforts, coupled with some modest gains in revenue, led to a fiscal year 2016 (2015-16) with a deficit of only $\$ 2,850$. After several years of five-figure deficits, this was welcoming news. In this current fiscal year (2016-17), ALCTS appears to be headed toward a similar or perhaps even smaller deficit. Expenses have been reduced in publications, in part by relying on the skills of staff for copyediting, and placing a page limit on each issue of Library Resources \& Technical Services (LRTS). Several ALCTS monographs are being published by ALA Editions, saving ALCTS the upfront costs of production in exchange for receiving future royalties.

In an attempt to realize reliable revenue from advertising, ALCTS entered into a contract with a firm to sell advertising for LRTS. The firm has been used with success by other ALA divisions, and proved a good value for ALCTS. The ALCTS Continuing Education Committee offerings have blown the doors off all projections this past fiscal year. With a couple of webinar series, the committee has done an excellent job of identifying issues of the moment presented by recognized practitioners. Web courses continue to sell out, even with the addition of more sessions, and an increase in class size for some sessions. A new Fundamentals web course has been developed and will be offered in the near future. The ALCTS Monographs Editorial Board is working on a new series, Sudden Positions, geared toward the person taking on a new role in technical services. Fundraising has been extremely successful this year, particularly with the addition of personal giving around the anniversary. Events such as the Midwinter Symposium, preconferences, and the ALCTS Exchange have all generated revenue, providing additional financial stability for the organization.

Reductions in expenses, coupled with revenue increases in some areas, have improved ALCTS's financial situation. However, declines in membership numbers, subscriptions, and book sales have taken a toll over several years, and longterm financial health is not yet restored. Creativity in programing, continuing education offerings, fundraising, and additional revenue generation will be needed.

\section{Equity, Diversity, Inclusion}

Perhaps in response to our turbulent times, we have felt the need to become more explicit and deliberate around the principles of equity, diversity, and inclusion both at the ALA level and within ALCTS. Among the activities sponsored by ALCTS, the 2017 Midwinter Symposium, organized under the leadership of Charles Wilt, took as its theme "Equity, Diversity, and Inclusion: Creating a New Future for Library Collections." Courtney Young opened the day, with Mark Puente closing. We waived registration fees for ALA Spectrum Scholars, and twelve chose to attend. Especially given the theme of the symposium, we wanted to support this important program focused on building diversity within our profession. We hope to establish the practice of free or subsidized registration to Spectrum Scholars for a variety of ALCTS programs.

Three of the speakers from the Midwinter Symposium moderated an ensuing e-Forum on equity, diversity, and inclusion in library technical services. Emily Drabinski, Paolo P. Gujilde, and Harrison W. Inefuku led a discussion that asked why equity, diversity, and inclusion are important and how librarians are integrating these values into technical services work.

In a lead-up to Annual, ALCTS held the virtual preconference "Diverse, Inclusive, and Equitable Metadata." Presentations highlighted how these values can inform the creation of metadata for institutional repositories, digital collections, and zines. Spectrum Scholars have been offered free registration for this online event, and many have indicated interest in attending.

At Annual 2017, ALCTS partnered with the Public Library Association (PLA) and the American Indian Library Association (AILA) to sponsor the program "Diversity, Inclusion and Social Justice in Technical Services." Also at Annual, we invited the Library Leadership and Management Association (LLAMA) to partner with us for a joint ALCTS/LLAMA Presidents' Program. Chicago's own Dorri McWhorter, CEO of the YWCA Metropolitan Chicago, was the program speaker, and her presentation centered on how we create social impact and a world where everyone has value. In addition to 
these events and activities, ALCTS sections have sponsored a variety of activities, including a Facebook Live event for Preservation Week, that have focused on these themes.

To make our commitment to these principles clear, the ALCTS Board discussed a draft equity, diversity, and inclusion statement at its Midwinter meetings. Jacquie Samples and Chelcie Rowell volunteered to draft a more comprehensive statement, and the Board voted on this statement at our Annual meeting. When adopted, it will stand alongside the ALCTS Mission Statement.

\section{ALCTS as a Vibrant, Relevant Organization}

We have developed a strong culture of evaluation and assessment of programs and services within ALCTS with the goal of maintaining a vibrant, relevant organization. In a five-year cycle, every division committee, section, and interest group undergoes an evaluation for renewal by the Organization \& Bylaws Committee. Additionally, ALCTS leadership submits reports on activities throughout the year. Since the adoption of the current Strategic Plan, which covers 2015-2018, the Planning Committee and the Board have worked together to make the reporting process a tool for fostering strategic thinking and evaluating current strategies. A template for the reports developed by the Planning Committee, asks ALCTS leadership to relate the activities of their group directly to the goals of the Strategic Plan. The Planning Committee compiles the reports, creating a critical tool used by the Board to assess progress on the goals.

For this year's report at Annual, the Planning Committee was asked to expand their analysis to include those areas of the Strategic Plan that have not been addressed by activities in the organization. This report should serve as a starting point for updating the current Strategic Plan, a process that will culminate with Annual in 2018.

The Leadership Development Committee, under Jennifer Bowen's guidance, generated a report that identifies gaps in professional development opportunities within ALCTS. The Board discussed this report at the 2017 Annual Conference. The information and recommendations it contains highlight potential opportunities for ALCTS to fill the gaps. It also suggests collaborations within ALCTS and with other ALA divisions.

CaMMS brought the Core Competencies for Cataloging and Metadata Librarians document to the Board for discussion at the 2017 Midwinter Meeting, and it was approved. The document was drafted by the Cataloging Competencies
Task Force of the ALCTS CaMMS Competencies and Education for a Career in Cataloging Interest Group and supplements the ALA Core Competences of Librarianship. Based on a literature review and a survey of advertisements for professional catalogers, it highlights three core competency areas and acknowledges a responsibility for advancing diversity issues within the broader information community.

The joint ALCTS/Library Information Technology Association (LITA) Metadata Standards Committee developed Principles for Evaluating Metadata Standards. The principles are intended to inform and support the development, maintenance, selection, and assessment of metadata standards. They include the guidance that metadata standards should be inclusive and transparent about historical and cultural biases.

We announced the creation of the CaMMS Lois Mai Chan Professional Development Grant this spring to a wellreceived response from the library community. This grant will provide librarians and paraprofessionals from underrepresented groups new to the metadata field with the opportunity to attend a professional conference and encourages professional development through active participation at the national level. CaMMS will appoint a grant jury in spring 2017, and the first grant will be awarded in 2018.

\section{Enough Said . . . Almost}

In looking back at the accomplishments and direction of ALCTS during this past year, it is easy to lose sight of the fact that volunteer members and a handful of exceptionally talented and extremely dedicated staff made all of these things (and so much more) possible. The ALCTS staff consists of Keri Cascio (Executive Director), Julie Reese (Continuing Education \& Meetings Manager) and Brooke Morris (Communications Specialist), each of whom deserves more thanks than we can ever give them. My heartfelt thanks go out to my fellow Executive Committee members who provided wise counsel and helpful levity throughout the year-Mary Beth Thomson (President-Elect), Norm Medeiros (Past-President) Andy Hart (Division Councilor) and Keri Cascio. Most especially, thank you to the members and ALCTS for your patience and support as I attempted to do my part in assuring a bright future for our organization.

I am grateful for the opportunity to have served as president of ALCTS, and humbled by the knowledge, skills, and commitment of those with whom I have served. 